\title{
PHARMACISTS' PERCEPTION ABOUT THEIR ROLES IN TUBERCULOSIS CONTROL PROGRAM IN MEDAN, INDONESIA
}

\author{
KHAIRUNNISA*, AZIZAH NASUTION \\ Department of Pharmaceutical Pharmacology, Faculty of Pharmacy, University of Sumatera Utara, Medan, Indonesia. \\ Email: nisa152@yahoo.com
}

Received: 19 December 2016, Revised and Accepted: 03 January 2017

\section{ABSTRACT}

Objective: To assess the pharmacists' perception about their roles in tuberculosis (TB) control program in Medan, Indonesia.

Methods: A cross-sectional study was conducted to assess the pharmacists' perception about their roles in TB control program in Medan, Indonesia using a validated questionnaire. The pharmacists involved in this study $(n=117)$ were asked to choose answering yes, no or do not know for their perception on their roles in TB control program. The collected data consisted of demographics (gender, age, place of practice, and working experience) and the pharmacists' perception on their roles in TB control program were organized and analyzed by applying descriptive and Chi-square analyses using Statistical Package for the Social Sciences (SPSS, version 19, Chicago, IL, USA) ( $\mathrm{p}<0.05$ was considered significant).

Results: Mean age of the participants was 38.6 \pm 11.7 (years). Most of them $(76.1 \%)$ were female. Distribution of the participants by place of practice: Pharmacy, 78.6\%; hospital, 20.5\%. Most of them (63.2\%) have heard about directly observed treatment short-course program. More than $90 \%$ of them realized that they could play their roles as providers, managers of anti-TB drugs, drug informants, ensurers for adherence to the TB treatment, educators for patients and publics on TB and its treatment. Only $26.5 \%$ of them knew that they could also play their role as inventors of early suspected TB in the community.

Conclusion: The study proved that the pharmacists' roles could be utilized and enhanced to optimize TB control programs in Indonesia.

Keywords: Pharmacists' role, Tuberculosis, Directly observed treatment short-course program.

(C) 2017 The Authors. Published by Innovare Academic Sciences Pvt Ltd. This is an open access article under the CC BY license (http://creativecommons. org/licenses/by/4. 0/) DOI: http://dx.doi.org/10.22159/ajpcr.2017.v10i4.16688

\section{INTRODUCTION}

Tuberculosis (TB) remains as one of the major global public health problems because of its increasing prevalence along with the increasing of endemic diseases especially in Asian countries. Indonesia was ranked as the fourth largest country with TB incidence in the world following India, China, and South Africa. Among all infectious diseases, TB was the second global leading cause of death following human immunodeficiency virus [1]. In 2014, as many as $1,600,000$ people in Indonesia were diagnosed as having TB with mortality rate of 100,000 [2]. Even though significant progresses have been made, yet efforts must be continuously done to support the vision of a world free of TB.

Successful prevention and care of TB are determined by many complex factors. All elements of societies including governments, health-care providers (doctors, nurses, and pharmacists), nongovernmental organizations, community leaders, religious leaders as well as publics must be fully involved in the prevention and ensuring the success of TB treatment. Pharmacists could play important roles in the prevention and management of TB. These roles include provision of adequate TB drugs, improvement of the TB patients' adherence to their prescribed medications, and patient education about TB and its treatment [3]. To implement these roles, pharmacists must realize the importance of their roles, have enough knowledge, and participate in the prevention and treatment programs of TB [4].

The contribution of pharmacists in prevention and treatment programs of TB varies across countries. In few countries, pharmacists have served as the frontline health-care providers and often a first point of contact for people with symptoms of TB such as cough [4]. A study showed that the involvement of pharmacists in TB treatment improved patients' adherence to the prescribed TB medications and directly improved therapeutic outcomes [5]. Many studies on TB have also been undertaken in Indonesia. However, studies on the role of pharmacists in prevention and treatment of this disease are still limited. A study on knowledge of pharmacists' role which involved 17 pharmacists as participants in TB control performed in Yogyakarta indicated that there was a lack of knowledge about the roles of the pharmacists in TB control [6].

Involvement of pharmacists in TB control in Indonesia is still limited. It is hoped by the Department of health Province of Sumatera Utara and Health Office of Medan that the pharmacists who practice in this area enhance their contribution in the prevention and treatment of TB. To response to these issues, this study focused on assessment of the pharmacists' perception about their roles in TB control program in Medan.

\section{METHODS}

A cross-sectional study was undertaken to assess the pharmacists' perception about their roles in TB control program in Medan. The pharmacists recruited as participants in this study were only limited to whom directly interact with TB patients in various health facilities including pharmacies, hospitals, and clinics $(\mathrm{n}=117)$. Ethical approval was obtained from the Ethical Committee, School of Nursing University of Sumatera Utara, Indonesia. A validated questionnaire [6,7] was distributed to the participants. They were asked to choose yes or no whether they have heard about directly observed treatment shortcourse (DOTS) and yes, no or do not know for their roles as care and drug information providers, teamwork of health-care providers, supervisors for anti-TB selection, early inventors of suspected TB patients, implementers to improve TB patients' adherence to their medications, educators for patients and people on TB and its treatment, and monitoring drug therapy. The participants were allowed for about 
15 minutes to answer all questions. The collected data consisted of demographics (gender, age, place of practice, and working experience) and their perceptions on their roles in TB control program were analyzed by applying descriptive and Chi-square analyses using Statistical Package for the Social Sciences (SPSS, version 19, Chicago, IL, USA) ( $p<0.05$ was considered significant).

\section{RESULTS}

As many as 117 pharmacists were recruited as participants in the study. Characteristics of the participants by gender, age, place of practice, and working experience are shown in Table 1. Mean age of the participants was $38.6 \pm 11.7$ (years). As demonstrated in Table 1, the majority of the participants $(76.1 \%)$ were female. According to the participants' distribution by health facility, it was found that most of them (78.6\%) practice in pharmacies. Less than a quarter of them (20.5\%) practice in hospitals. The participants' working experience was $9.45 \pm 8.4$ (years). Most of the participants have worked for less of 10 years.

Understanding on DOTS program and sources of information obtained by the participants are listed in Table 2 . This study proved that $74(63.2 \%)$ of the pharmacists have heard and known about DOTS program. Of the 74 participants, as many as 30 participants (40.5\%) and 27 participants (36.5\%) got information about DOTS program through seminars and formal education at universities, respectively. As many as $43(36.8 \%)$ of them have still never heard about the DOTS program.

The pharmacists' perception about their roles in TB control program is listed in Table 3. This study indicated that almost all of the pharmacists $(97.4 \%)$ argued that they could provide and manage the use of anti-TB medicines. Most of them (97.4\%) also realized that they could provide information on anti-TB medicines. Most of the pharmacists (81.2\%) realized that they should integrate and collaborate with other healthcare providers in the care of TB patients. This study found that $77.8 \%$ of the pharmacists realized that they could serve as supervisors for TB patients regarding their medications as homecare services. Most of the participants $(91.5 \%)$ knew that they could play an important role to ensure compliance of TB patients with their medications.

With respect to the pharmacists' role as educators, it was proved that $94.9 \%$ of them realized that they could monitor and educate patients about the side effects of anti-TB drugs. The majority of the participants $(90.6 \%)$ were aware of the importance of their involvement to educate publics on TB and its treatment. In addition, this study also proved that $78.6 \%$ of the participants realized that they could monitor the distribution and use of TB drugs in communities. Less than one-third of the participants $(26.5 \%)$ realized that they could play important role as an early inventor of TB patients in communities.

\section{DISCUSSIONS}

DOTS is the strategy recommended by the World Health Organization in the prevention and treatment of TB worldwide. The DOTS program ensures that patients take each dose of anti-TB medication as prescribed and helps prevent the emergence of drug resistance $[8,9]$. Promotion of adherence to the prescribed TB medication is implemented through a patient-centered approach includes facilitating access to treatment, choosing with the patients' most convenient time and place for direct observation of treatment, and when possible, providing other social and medical services [10]. Pharmacists as a part of health-care providers should know, understand, and participate in the DOTS program. Findings on the pharmacists' perceptions on their role on TB management vary from one study to another.

As previously mentioned only $63.2 \%$ of the pharmacists have known about DOTS program from different sources of information. This means improvement of the participants' understanding on DOTS program is required. In the future, policy makers should place priority on improving the pharmacists' knowledge on TB. In the TB control programs, all
Table 1: Characteristics of the participants by gender, age, place of practice, and working experience $(n=117)$

\begin{tabular}{llll}
\hline Variable & Category & Frequency $\mathbf{n ~ ( \% ) ~}$ & $\mathbf{p}$ \\
\hline Gender & Female & $89(76.1)$ & $<0.001$ \\
& Male & $28(23.9)$ & \\
Age (years) & $21-30$ & $35(29.9)$ & 0.040 \\
& $31-40$ & $41(35)$ & \\
& $41-50$ & $15(12.8)$ & $<0.001$ \\
Place of practice & $51-60$ & $26(22.2)$ & \\
& Pharmacy & $92(78.6)$ & $<0.001$ \\
Working & Hospital & $24(20.5)$ & \\
experience & Clinic & $1(0.9)$ & \\
& $1-10$ years & $76(65.0)$ & \\
& & & \\
& $11-20$ years & $31(26.5)$ & \\
& $21-30$ years & $8(6.8)$ & \\
& $30-40$ years & $2(1.7)$ & \\
\hline
\end{tabular}

Table 2: Understanding on DOTS program and sources of information obtained by the participants $(n=117)$

\begin{tabular}{lll}
\hline Variable & Category & $\begin{array}{l}\text { Frequency } \\
\text { n (\%) }\end{array}$ \\
\hline Have heard about DOTS & Yes & $74(63.2)$ \\
& No & $43(36.8)$ \\
Sources of information & Formal education at & $30(40.5)$ \\
& universities & $3(4.1)$ \\
& Newspapers & $27(36.5)$ \\
& Seminars & $14(18.9)$ \\
\hline
\end{tabular}

DOTS: Directly observed treatment short-course

Table 3: Pharmacists' perception about their roles in TB control program $(n=117)$

\begin{tabular}{|c|c|c|c|}
\hline \multirow[t]{2}{*}{ Roles of pharmacists } & \multicolumn{3}{|c|}{ Pharmacists' perception n (\%) } \\
\hline & Yes & No & $\begin{array}{l}\text { Do not } \\
\text { know }\end{array}$ \\
\hline $\begin{array}{l}\text { To provide and manage the } \\
\text { use of anti-TB medicines }\end{array}$ & $114(97.4)$ & $1(0.9)$ & $2(1.7)$ \\
\hline $\begin{array}{l}\text { To provide information on } \\
\text { anti-TB medicines }\end{array}$ & $114(97.4)$ & 0 & $3(2.6)$ \\
\hline $\begin{array}{l}\text { To integrate and collaborate } \\
\text { with other health-care } \\
\text { providers in the care of TB } \\
\text { patients }\end{array}$ & $95(81.2)$ & $14(12.0)$ & $8(6.8)$ \\
\hline $\begin{array}{l}\text { Supervisors to the TB patients } \\
\text { regarding their medications }\end{array}$ & $91(77.8)$ & $21(17.9)$ & $5(4.3)$ \\
\hline $\begin{array}{l}\text { Early inventors of patients } \\
\text { with suspected TB }\end{array}$ & $31(26.5)$ & $72(61.5)$ & $14(12.0)$ \\
\hline $\begin{array}{l}\text { To improve adherence of TB } \\
\text { patients to their medications }\end{array}$ & 107 (91.5) & $8(6.8)$ & $2(1.7)$ \\
\hline $\begin{array}{l}\text { To monitor and educate } \\
\text { patients about side effects of } \\
\text { TB medications }\end{array}$ & $111(94.9)$ & $3(2.6)$ & $3(2.6)$ \\
\hline $\begin{array}{l}\text { To monitor the distribution } \\
\text { and use of TB drugs in } \\
\text { communities }\end{array}$ & $92(78.6)$ & $17(14.5)$ & $8(6.8)$ \\
\hline $\begin{array}{l}\text { To educate people on TB and } \\
\text { its treatment }\end{array}$ & $106(90.6)$ & $5(4.3)$ & $6(5.1)$ \\
\hline To monitor drug therapy & $104(88.9)$ & $10(8.5)$ & $3(2.6)$ \\
\hline
\end{tabular}

TB: Tuberculosis

elements of society including pharmacists must have roles [11]. A pharmacist plays an important role in TB control, especially in aspects related to the provision and use of TB medicines [3]. According to this study, nearly all of the pharmacists argued that they could 
manage the use of anti-TB medicines and provide information about the medicines. The results of this study are consistent with the previous study conducted in Yogyakarta in which all participants in both studies were aware that they had pivotal roles to provide accurate selection of efficacious and safe TB drugs as well as drug information to patients with TB [6].

Most of the pharmacists (81.2\%) realized that they should integrate and collaborate with other health-care providers in the care of TB patients. This finding is slightly different from a previous study undertaken in Yogyakarta. The previous study found that all participants knew that they must collaborate with other health-care providers in the care and control of TB [6]. The Indonesian government has urged all health-care providers and publics to collaborate in TB control programs in Indonesia [11]

This study found that most of the pharmacists realized that they could serve as supervisors to ensure that the patients adhere and comply with their medications as homecare services. This finding supported a study undertaken in Yogyakarta that revealed that one of the pharmacists' roles was to guarantee and ensure compliance of TB patients with their medications [6]. Nonadherence to the prescribed TB medications is one of the risk factors for development of multi-drug resistant TB (MDR-TB) which in turn requires the more expensive and toxic medications which may finally result in treatment failure $[12,13]$. It has been found that Indonesia is one of the 27 MDR-TB high burden countries worldwide, with estimated 6,800 new cases every year. The national MDR-TB prevalence is estimated at $1.9 \%$ among new TB cases and $12 \%$ any retreatment TB cases [14]. A prospective study conducted in India found that provision of counseling to TB patients $(n=39)$ improved their adherence to their medications [15]. Thus, Indonesian pharmacists should also be encouraged to involve in improving the TB patients' adherence to their medications.

With respect to the pharmacists' role as educators, it was proved that most of them realized that they could monitor and educate patients about the side effects of anti-TB drugs. A similar also proved that another pharmacists' role was to monitor and educate patients about the side effects associated with the use of TB medicines [6]. Awareness of this role is important, because the TB patients need information about side effects of their medications and what actions to be taken to resolve these problems. A study on the prevalence of adverse drug reactions experienced by TB patients in a tertiary care hospital in India showed that the majority of the patients had the wrong opinion about their treatments because they felt that their conditions were worsened after taking TB drugs [16]. Thus, sufficient knowledge of TB patients about their medications is important. The majority of the participants $(90.6 \%)$ were aware of the importance of their involvement to educate publics on TB and its treatment. Curing the individual patient and minimizing the transmission of Mycobacterium tuberculosis to other persons are the main strategy to manage TB in the community. Thus, successful treatment of TB has benefits both for the individual patient and the community in which the patient resides [17]. In addition, most of the participants realized that they could monitor the distribution and use of TB drugs in communities. These findings indicated that the pharmacists have the capacity to contribute to TB program. In reality, this potency remains underutilized. To realize this potential, the Department of Health needs to collaborate with the Indonesian Pharmacist Association and other organizations to establish strategies with regulatory enforcement.

This study indicated that less than one third of the participants realized that they could play important role as an early inventor of TB patients in communities. A systematic review on delays in diagnosis and treatment of pulmonary TB in India found that pharmacies were the first health-care providers visited by TB suspect patients before visiting a diagnostic facility or medical practitioner [18]. Early detection of TB patients is important for early treatment and avoidance of the disease transmission. This finding must be highlighted and considered for the future policy of TB prevention and treatment to support the vision of the world free of TB.

\section{CONCLUSIONS}

Based on this study, it could be concluded that most of the pharmacists realized that they could play important roles in the prevention and care of TB especially in providing and management of TB medications, patients' adherence, monitoring of anti-TB medications and their side effects. It should be highlighted by the policy makers that the pharmacists' potency should be utilized and enhanced especially in early detection of TB cases in communities to optimize TB care and control.

\section{ACKNOWLEDGMENT}

We would like to thanks to Directorate General of High Education, Indonesia, for providing the financial support to this study. We would also like to thanks to the Indonesian Pharmacists Association, Province of Sumatera Utara for the support provided in implementing this study.

\section{REFERENCES}

1. World Health Organization. Global Tuberculosis Report. Geneva: WHO; 2014.

2. TB Statistics-Global, Regional, and High Burden. Available from: http://www.tbfacts.org/tb-statistics/. [Last accessed on 2016 Oct 07]

3. Mkele G. The role of the pharmacist in TB management. S Afr Pharm J 2010;77(2):18-20

4. Nakatani H, Buchmann M. The role of the pharmacist in tuberculosis care and control, Singing Ceremony. WHO FIP Joint Statement; 2011. p. 1-4.

5. Venkatapraveen A, Rampure MV, Patil N, Shivanad SS, Lakshmi DP. Assessment of clinical pharmacist intervention to improve compliance and health care outcomes of tuberculosis patient. Der Pharm Lett 2012;4(3):931-7.

6. Nanang MY, Djoko W, Bambang SR, Ika PS. Tuberculosis-related to knowledge, adverse drug reactions, clinical outcome, adherence in tuberculosis patients and pharmacist role, a preliminary survey for pharmacist intervention model development. IJPCR 2016;85 Suppl:517-22.

7. Thamby SA, Subramani P. Seven-star pharmacist concept of WHO. J Young Pharm 2014;6(2):1.

8. Bayer R, Wilkinson D. Directly observed therapy for tuberculosis: History of an idea. Lancet 1995;345(8964):1545-8.

9. Squire SB, Wilkinson D. Strengthening "DOTS" through community care for tuberculosis. BMJ 1997;315(720):1395-6.

10. Frieden TR, Sbarbaro JA. Promoting adherence to treatment for tuberculosis: The importance of direct observation. Bull World Health Organ 2007;85(5):407-9.

11. Kementerian Kesehatan Republik Indonesia. Public Private Mix Pengendalian Tuberkulosis di Indonesia 2011-2014. Jakarta: Kementerian Kesehatan Republik Indonesia; 2011b.

12. Bisht RE, Katiyar AL, Singh RA, Mittal PI. Antibiotic resistance-A global issue of concern. Asian J Pharm Clin Res 2009;2(2):34-9.

13. Nieuwlaat R, Wilczynski $N$, Navarro $T$, Hobson $N$, Jeffery $R$, Keepanasseril A, et al. Interventions for enhancing medication adherence. Cochrane Database Syst Rev 2014;CD000011.

14. World Health Organization. 2014. Available from: http://www.searo. who.int/indonesia/topics/tb/en/. [Last accessed on 2016 Oct 16].

15. Bhardwaj AL, Kumar RA, Dabas VI, Alam NI. Assessment and enhancing adherence to treatment regimen in tuberculosis out patients. Int J Pharm Pharm Sci 2012;4(3):517-22.

16. Siddiqui S, Ali Baig MM, Jaffer S, Raza Ansari SF. Study on prevalence of adverse drug reactions in patients suffering from tuberculosis in a tertiary care hospital. Int J Pharm Pharm Sci 2016;8(8):375-7.

17. Nahid P, Dorman SE, Alipanah N, Barry PM, Brozek JL, Cattamanchi A, et al. Executive Summary: Official American Thoracic Society/Centers for Disease Control and Prevention/Infectious Diseases Society of America Clinical Practice Guidelines: Treatment of Drug-Susceptible Tuberculosis. Clin Infect Dis 2016;63(7):853-67.

18. Sreeramareddy CT, Qin ZZ, Satyanarayana S, Subbaraman R, Pai M. Delays in diagnosis and treatment of pulmonary tuberculosis in India: A systematic review. Int J Tuberc Lung Dis 2014;18(3):255-66. 